\title{
Genomic alterations in Warthin tumors of the parotid gland
}

\author{
SILKE WEMMERT ${ }^{1}$, VIVIENNE WILLNECKER $^{1}$, BIRGIT SAUTER $^{1}$, SEBASTIAN SCHUH $^{1}$, \\ CHRISTIAN BRUNNER ${ }^{1}$, RAINER MARIA BOHLE ${ }^{2}$, STEFFI URBSCHAT ${ }^{3}$ and BERNHARD SCHICK ${ }^{1}$ \\ ${ }^{1}$ Department of Otolaryngology, ${ }^{2}$ Institute of Pathology, and ${ }^{3}$ Department of Neurosurgery, \\ Saarland University Medical Center, D-66421 Homburg/Saar, Germany
}

Received December 2, 2013; Accepted January 21, 2014

DOI: $10.3892 / o r .2014 .3028$

\begin{abstract}
Despite the fact that Warthin tumors are the second most common type of benign salivary gland tumors, information regarding genetic alterations is extremely limited, and the tumorigenesis of these tumors has not been elucidated. The present results of the largest series of 30 tumors analyzed by comparative genomic hybridization $(\mathrm{CGH})$ to date confirmed previous genetic findings and identified significant new candidate regions. The most commonly observed alterations were deletions of the short arm of chromosome 8 , followed by deletions on $9 \mathrm{p}$. Further representative changes were deletions on $16 \mathrm{p}$ and $22 \mathrm{q}$ with the minimal overlapping region at 16p12p13.1 and 22q12.1q12.3. Moreover, we indicated two different patterns of chromosomal aberrations. One group harbors deletions on $8 \mathrm{p}$ partly apparent with deletions on $9 q, 11 q 15 q, 16 p$ and 22 . The second group shows gains on 22 , partly apparent with gains on $1 \mathrm{p}$ and $20 \mathrm{q}$ and deletions on 9p. This leads to the assumption that Warthin tumors, in particular those with a high number of alterations, can be divided into two different genetic groups based on the pattern of numerical chromosomal aberrations. Further studies should address whether these subgroups also reflect a different clinical presentation.
\end{abstract}

\section{Introduction}

Warthin tumors (WTs) are the second most common benign salivary gland tumors and account for $\sim 15 \%$ of all epithelial parotid gland tumors. They are well encapsulated lesions with cystic and solid areas consisting of an oncocytic epithelial cell and a variable stroma component with lymphoid tissue. Malignant alteration is very rare and surgical resection is the most common treatment modality (1-3).

Correspondence to: Dr Silke Wemmert, Department of Otolaryngology, Saarland University Medical Center, D-66421 Homburg/Saar, Germany

E-mail: silke.wemmert@uks.eu

Key words: salivary gland, Warthin tumor, comparative genomic hybridization, genetic alterations
To date, tumorigenesis of WTs is unknown. Two different theories for WT development are currently being discussed. One is the hypothesis of heterotopia, which implies that the tumor results from proliferating ductal cells of the salivary gland that were entrapped in parotid lymph nodes during embryonal life. The second theory suggests that a WT initially develops in the parotid lymph nodes as an adenomatous epithelial proliferation in response to a yet unidentified stimulus, such as tobacco, with concomitant lymphocytic infiltration (1). The putative link between tobacco consumption as one of the aetiologic factors associated with the development of WTs is in line with the observation that the incidence of WTs in smokers is eight times higher than that in non-smokers (4).

To date, only limited cytogenetic information is available for WTs. The majority of tumors analyzed to date by conventional cytogenetics have an apparently normal karyotype. Only $10 \%$ of WTs exhibit genetic alterations (5-13). Based on the detected genetic alterations, three main stemline groups are proposed for WTs: i) normal karyotype, ii) numerical changes only, i.e. loss of Y chromosome or trisomy/ monosomy 5, and iii) reciprocal translocations such as the $\mathrm{t}(11 ; 19)$ translocation resulting in the $M A M L 2 / C R T C 1$ fusion gene (11). This translocation is characteristic for mucoepidermoid carcinoma (MEC) while a possible derivation of certain MECs from WTs is under discussion (11-15). Identification of $6 p$ translocations suggests that the short arm of chromosome 6 contains a region involved in the origin of WTs $(6,8)$. Identification of clonal alterations in almost half of the cases further supports that this lesion is a 'true' neoplasm rather than an autoimmune or hypersensitivity related tumor-like proliferation, as previously suggested (16).

To the best of our knowledge, only one molecular cytogenetic study using comparative genomic hybridization (CGH) analysis on WTs has been published to date. The authors of this previous study observed several chromosomal gains and losses in a cohort of 15 tumors. Frequent chromosomal losses were reported at $12 q(47 \%), 17 p(53 \%)$ and $22 q(73 \%)$, whereas frequent chromosomal gains were located at $4 \mathrm{q}(60 \%), 6 \mathrm{q}$ (33\%) and 13q (67\%) (17). This high frequency of detected alterations by molecular cytogenetic analysis compared to conventional cytogenetics underlines the need and importance for investigating native tumor material other than cell culture preparations to detect chromosomal alterations.

Herein, we present a second molecular cytogenetic study of WTs with the largest cohort of 30 tumors to date in order 


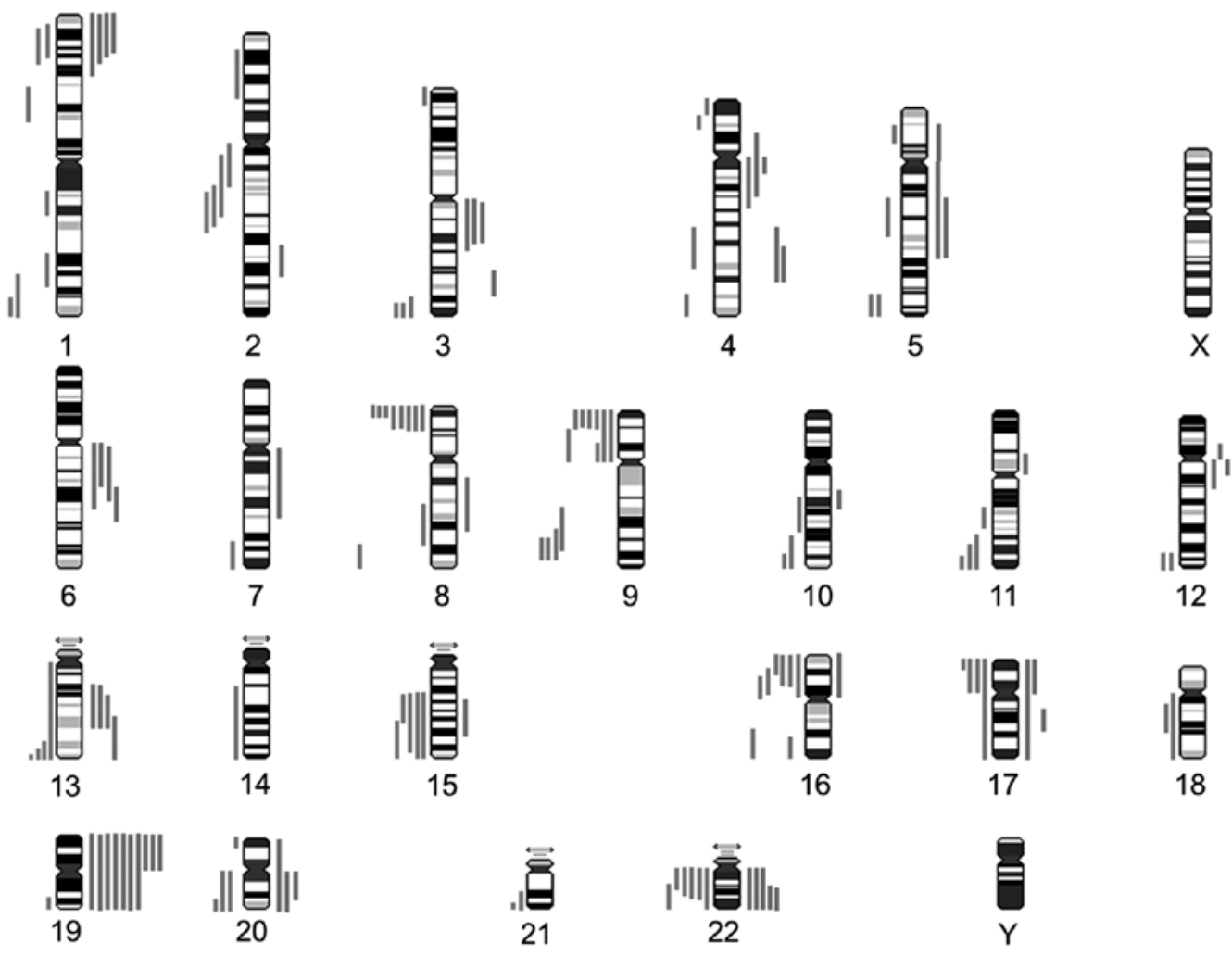

Figure 1. Summary of the chromosomal alterations identified in the Warthin tumors by CGH. Bars on the left side indicate losses of chromosomal material and bars on the right side represent gains.

to confirm previous reported alterations and to detect new significant chromosomal aberrations because of the higher number of tumor samples.

\section{Materials and methods}

Patient characteristics. A total of 30 patients (14 female and 16 male), with a median age of 57 years (19-87 years), who received a parotidectomy with the purpose to remove a parotid gland mass between the period 2000 and 2006 at the Department of Otolaryngology, University Hospital Homburg/ Saar, Germany was investigated. All surgeries were primary surgeries treating no recurrent disease. Prior to surgery, all patients were informed in regards to the protocol and provided their written consent for donating tissue for research purposes. Tissue was snap frozen immediately after removal at $-80^{\circ} \mathrm{C}$ for CGH analysis. The diagnosis of benign WT was confirmed by detailed histopathological evaluation in all tumors. To date, none of the patients has developed a tumor recurrence.

$C G H$. We obtained DNA using phenol/chloroform extraction. Tumor DNA and reference DNA were labeled with biotin and digoxigenin by nick translation according to the manufacturer's protocol (Roche Diagnostics, Mannheim, Germany). Tumor DNA and reference DNA, 600 ng each, were hybridized with Cot1-DNA (Roche Diagnostics) to normal chromosome metaphase spreads from peripheral blood lymphocytes prepared following standard procedures. After three days of hybridization at $37^{\circ} \mathrm{C}$, post-hybridization washes were performed at a stringency of $50 \%$ formamide $/ 2 \mathrm{X}$ standard saline citrate
(SSC), $2 \mathrm{X} \mathrm{SSC}$ and $0.1 \mathrm{X} \mathrm{SSC}$ at $45^{\circ} \mathrm{C}$. Tumor DNA was visualized with fluorescein-isothiocyanate (Vector Laboratories, Inc., Burlingame, CA, USA), reference DNA with rhodamine (Roche Diagnostics) and counterstained with an anti-fade solution containing DAPI (4,6-diamidino-2-phenylindole) (Vector Laboratories). Fluorescence images were captured using an Olympus BX 61 fluorescence microscope with a cooled charged-coupled device camera. Image processing was performed by using the computerized ISIS digital image analysis software system (MetaSystems, Altlussheim, Germany). Average ratio profiles were determined from analysis of 12-15 metaphases. The thresholds used for ratio profiles were 1.2 for gains, and 0.8 for losses.

Due to the suppression with Cot1-DNA, the fluorescence intensities were not representative at chromosome regions with tandem repetitive DNA clusters, that is at the heterochromatic blocks on chromosomes 1, 9, 16, and $\mathrm{Y}$ at the centromeric regions and along the short arms of acrocentric chromosomes. These areas and the whole sex chromosomes were excluded from CGH evaluation. Additionally, the chromosomal regions, such as 1p34pter, 19 and 22 were interpreted cautiously, particularly as they are prone to problems associated with the different hybridizability of their GC-rich regions (18).

\section{Results}

CGH. Chromosomal alterations were detected in a nonrandom distribution in 27 out of the 30 hybridized WTs by CGH analysis. The mean number of imbalances was 5.3 (range from 0 to 21). Detection of losses was more frequent 
Table I. Results obtained from CGH analysis of 30 Warthin tumors.

\begin{tabular}{|c|c|c|c|c|c|c|}
\hline Tumor & $\begin{array}{l}\text { Age/ } \\
\text { Gender }\end{array}$ & Chromosomal gains & Chromosomal losses & $\begin{array}{l}\text { No. of } \\
\text { gains }\end{array}$ & $\begin{array}{l}\text { No. of } \\
\text { losses }\end{array}$ & $\begin{array}{l}\text { Total no. of } \\
\text { imbalances }\end{array}$ \\
\hline 1 & $75 / \mathrm{F}$ & $\begin{array}{l}3 \mathrm{q} 11 \mathrm{q} 21,4 \mathrm{q} 28 \mathrm{q} 31 \\
6 \mathrm{q} 11 \mathrm{q} 22.2,12 \mathrm{q} 11 \mathrm{q} 13\end{array}$ & $22 q 11 q 12$ & 4 & 1 & 5 \\
\hline 2 & $56 / \mathrm{F}$ & $\begin{array}{l}3 q 11 q 13.3,4 q 26 q 31.3 \\
8 q 13 q 22,13 q 14 q 22\end{array}$ & & 4 & 0 & 4 \\
\hline 3 & $52 \mathrm{~F}$ & - & - & 0 & 0 & 0 \\
\hline 4 & $58 / \mathrm{M}$ & $5 q 14 q 23,6 q 21 q 22$ & - & 2 & 0 & 2 \\
\hline 5 & $50 / \mathrm{M}$ & $13 q 22 q$ ter & & 1 & 0 & 1 \\
\hline 6 & $53 / \mathrm{M}$ & - & - & 0 & 0 & 0 \\
\hline 7 & $50 / \mathrm{M}$ & - & 8q24.1qter & 0 & 1 & 1 \\
\hline 8 & $57 / \mathrm{M}$ & - & $5 \mathrm{p} 14$ & 0 & 1 & 1 \\
\hline 9 & $87 / \mathrm{F}$ & $4 q 11 q 13.1,12 q 11 q 12$ & 1p33p36.1, 16p11.1p12 & 2 & 2 & 4 \\
\hline 19 & $56 / \mathrm{M}$ & 19 & - & 2 & 0 & 2 \\
\hline 20 & 39/M & $19 p$ & $2 q 12 q 23,8 p 23.1 p t e r$ & 1 & 2 & 3 \\
\hline 25 & $56 / \mathrm{M}$ & - & $9 \mathrm{p} 11 \mathrm{p} 21$ & 0 & 1 & 1 \\
\hline 26 & $51 / \mathrm{M}$ & - & $1 \mathrm{p} 22.1 \mathrm{p} 31.1,10 \mathrm{q} 24.3 \mathrm{qter}$ & 0 & 2 & 2 \\
\hline 27 & $42 / \mathrm{M}$ & - & - & 0 & 0 & 0 \\
\hline 28 & $64 / \mathrm{F}$ & - & $17 p$ & 0 & 1 & 1 \\
\hline 22 & $71 / \mathrm{F}$ & $\begin{array}{l}\text { 1p33pter, } 17 \mathrm{p} 11 \text { pter, } 19 \\
\underline{20 \mathrm{q} 11.1 \mathrm{q} 13.1, \underline{22 \mathrm{q}}}\end{array}$ & 9p22pter, 13q33qter, 20p13pter & 6 & 3 & 9 \\
\hline 23 & $56 / \mathrm{F}$ & 1p32.3pter, $19 \mathrm{p}$, 22q12.2qter & $\begin{array}{l}\text { 3q28qter, 4q33qter, 5q14q21, } \\
\text { 9p11p13, 9p23pter }\end{array}$ & 3 & 5 & 8 \\
\hline 24 & $66 / F$ & 1p34.1pter, 19, 20 & 1q43qter, 9p & 5 & 2 & 7 \\
\hline 29 & $19 / \mathrm{M}$ & 1p35pter, 17p, 19, 22 & $5 \mathrm{p} 11 \mathrm{p} 12$ & 5 & 1 & 6 \\
\hline 30 & $57 / \mathrm{F}$ & $11 \mathrm{p} 11.1 \mathrm{p} 12,19, \underline{22}$ & $2 \mathrm{q} 21.3 \mathrm{q} 24.3,4 \mathrm{q} 26 \mathrm{q} 31.1$ & 4 & 2 & 6 \\
\hline 21 & $61 / \mathrm{F}$ & $\begin{array}{l}15 \mathrm{q} 21.2 \mathrm{q} 24,17,19 \\
\underline{20 \mathrm{q}}, \underline{22 \mathrm{q} 12.3 \mathrm{qter}}\end{array}$ & $2 q 21.1 \mathrm{q} 24.2,8 \mathrm{p} 23.1 \mathrm{pter}, 9 \mathrm{p}$ & 6 & 3 & 9 \\
\hline 10 & $61 / \mathrm{F}$ & $\begin{array}{l}\text { 2q32.1q33, 3q25.3q26.3 } \\
4 \mathrm{p} 11 \mathrm{p} 14,4 \mathrm{q} 11 \mathrm{q} 21.3\end{array}$ & $\begin{array}{l}\text { 15q21.1q22.3, 16p13.1pter, } \\
\text { 22q11.1q13.1 }\end{array}$ & 4 & 3 & 7 \\
\hline 11 & $62 / \mathrm{M}$ & $\begin{array}{l}5 \mathrm{p} 11 \mathrm{p} 14,5 \mathrm{q} 11 \mathrm{q} 23.3 \\
6 \mathrm{q} 11 \mathrm{q} 22.1\end{array}$ & $\begin{array}{l}\text { 3p24.3pter, 5q34qter, 7q33qter, } \\
\text { 8p23.1pter, 9q32q34.1, } \\
\text { 11q23.1qter, 12q24.2qter, } \\
\text { 13q32qter, 15q21.1qter, 16p12pter, } \\
\text { 16q23qter, 17, 18q, 19q13.3qter, 20q, } \\
\text { 21q22.1qter, 22q12.2qter }\end{array}$ & 3 & 18 & 21 \\
\hline 12 & $45 / \mathrm{F}$ & $\begin{array}{l}3 q 11.2 q 13.3,4 q 11 q 22 \\
6 q 12 q 21,13 q 14.3 q 22\end{array}$ & $\begin{array}{l}\text { 8p23.1pter, 9q32q34.1, 10q26.1qter, } \\
\text { 11q23.3qter, 12q24.2qter, 14q21qter, } \\
\text { 15q23qter, 16q22qter, 17p, } \\
\text { 20q13.2qter, 22q11.1q13.2 }\end{array}$ & 4 & 11 & 15 \\
\hline 13 & $64 / \mathrm{M}$ & $19 p$ & $\begin{array}{l}\text { 1p34.1p36.2, 1q21.2q23, 1q32.1q41, } \\
\text { 2p16p23, 8p21.3pter, 8q21.3q23, } \\
\text { 9q22.1q33, 10q22.1q24.1, } \\
\text { 11q14.1q22.1, 15q21.1q25, } \\
\text { 16p11.2p13.1, 18q12.1q21.3, 20q, } 22\end{array}$ & 1 & 13 & 14 \\
\hline 18 & $63 / \mathrm{M}$ & $12 \mathrm{p} 11 \mathrm{p} 12.1$ & $\begin{array}{l}\text { 2q11.1q14.3, 3q28qter, 8p21.3pter, } \\
\text { 15q21.3qter, 22q11.1q12.3 }\end{array}$ & & 5 & 6 \\
\hline 14 & $61 / \mathrm{F}$ & $\begin{array}{l}7 q 11.1 q 31.2,10 q 21.2 q 22.2 \\
13 q 14.1 q 22\end{array}$ & 1q41qter, 8p22pter, 16p & 3 & 3 & 6 \\
\hline
\end{tabular}


Table I. Continued.

\begin{tabular}{|c|c|c|c|c|c|c|}
\hline Tumor & $\begin{array}{c}\text { Age/ } \\
\text { Gender }\end{array}$ & Chromosomal gains & Chromosomal losses & $\begin{array}{l}\text { No. of } \\
\text { gains }\end{array}$ & $\begin{array}{l}\text { No. of } \\
\text { losses }\end{array}$ & $\begin{array}{l}\text { Total no. of } \\
\text { imbalances }\end{array}$ \\
\hline 15 & $80 / \mathrm{F}$ & $17 q 21.2 q 22,19$ & 5q34qter, 9p23pter, 13q34qter & 3 & 3 & 6 \\
\hline 16 & $57 / \mathrm{M}$ & - & $\begin{array}{l}\text { 3q27qter, 4p16pter, 8p22pter, } \\
\text { 9q31q34.1, 16p12pter, } \\
\text { 17p13pter, 21q22.3qter }\end{array}$ & 0 & 7 & 7 \\
\hline 17 & 46/M & 19 & 8p23.1pter, 9p23pter, 11q24qter & 2 & 3 & 5 \\
\hline
\end{tabular}

F, female; M, male. Tumors with a higher number of CNAs (6 or more) show two different patterns of alterations: one is characterized by deletions affecting 8p, 9q, 11q 15q, 16p and 22 (bold type); in the second one gains of 22 were partly apparent with gains on 1p and 20q and losses of $9 p$ (underlined).

Table II. Chromosomal alterations and putative target genes
observed by CGH.

Figure 2. Consensus regions at chromosome arm 6q, 8p, 9p, 9q, 13q and 16p. Bars on the left side indicate losses of chromosomal material and bars on the right side represent gains.

than gains (93 vs. 67 , mean 3.1 vs. 2.3 ). The graphical representation of the genetic alterations is shown in Fig. 1. The clinical data and chromosomal imbalances are summarized in Table I.

The most commonly observed alterations were deletions of the short arm of chromosome $8(30 \%)$, followed by deletions of $9 p(23 \%)$. Further representative changes were deletions on chromosome arm 16p and $22 \mathrm{q}$ with the minimal overlapping region at $16 \mathrm{p} 12 \mathrm{p} 13.1$ and $22 \mathrm{q} 12.1 \mathrm{q} 12.3$ in $20 \%$ of the investigated tumors (Fig. 2). Moreover, in 17\% of the cases, gains at $4 \mathrm{q}, 15 \mathrm{q}$ and $22 \mathrm{q}$ were detected. At a lower frequency, deletions on $2 q, 9 q$ and $17 p$ and gains on $6 q$ and $13 q$ were observed (13\% each), with the minimal overlapping regions at $13 \mathrm{q} 22$ and 6q21q22.1. An overview of the most commonly observed alterations and putative candidate genes is shown in Table II.
Table II. Chromosomal alterations and putative target genes served by $\mathrm{CGH}$

Our data indicate that almost all tumors with a higher number of copy number alterations (6 or more) are able to be distinguished by two different patterns of alterations. The first one is characterized by deletions affecting 8p, 9q, 11q 15q, 16p and 22 , whereas in the second one gains of 22 were partly apparent with gains on $1 p$ and $20 q$ and losses on $9 p$ (Table I).

\section{Discussion}

Herein, we present our CGH study on 30 WTs that displayed numerous chromosomal alterations. In regard to only one available CGH study of $15 \mathrm{WTs}$, previous reported chromosomal aberrations but also novel regions of interest in this tumor have been observed.

Giefing et al (17) revealed in his subset of $15 \mathrm{WTs}$, that losses of chromosome $22,17 p$ and $12 q(73,53$ and $47 \%$, respectively) were the most consistent alterations. Chromosomal gains were observed most frequently on 13q, 4q, 6q and 2q (67, 60, 33 and $27 \%$, respectively). The present study confirms these 
commonly observed losses and gains; however, at an approximately one-third lower incidence of the affected tumors when compared to Giefing et al (17).

Deletions of the terminal region of $9 q$ were observed in $13 \%$ of our tumors and were also noted by Giefing et al (17) in their smaller cohort at a percentage of $13 \%$ in their tumors. In this region, GAS1 on 9q21.33 and TSC1 on 9q34.13 are located. The tumor-suppressor gene GASI has previously been shown to play a role in other entities such as myeloid malignancies (19). Loss of TSC genes has been reported to result in tumor development by its constitutive activation of MTOR and downstream signaling elements (20).

In accordance to Giefing et al (17), our study revealed additional deletions affecting chromosomes 16, 17 and 22 with the minimal overlapping region on 16p12p13.1, 17p13 and $22 \mathrm{q} 12$. Close to the minimal overlapping region on 16p12p13.1 (Fig. 2), several significant candidate genes are located which are known to be involved in cell cycle regulation and apoptosis, for example MAPK3, LITAF and ERCC4. Furthermore, for other tumors such as breast carcinomas, colorectal tumors and anaplastic thyroid cancers, the important role of deletions of the short arm of chromosome 16 has been previously demonstrated (21-23).

Notably, Giefing et al (17) as well as our study revealed gains on 6q as a frequent event in WTs. In the delineated consensus region on $6 \mathrm{q} 21$, which was affected in $33 \%$ of our tumors, the $F Y N$ oncogene is located. $F Y N$ belongs to the $\mathrm{Src}$ kinases, which are key upstream mediators of both the PI3-K and MAPK signaling pathways, and have been shown to play important roles in cell proliferation, migration and survival (24). In contrast, cytogenetic examination of the cultured tumor cells showed normal karyotypes in the majority of WTs. Nevertheless, one study also revealed non-clonal deletions of chromosome 6 as well as a deletion of 6q21 in 3 of 13 cultured tumors (10). Notable, in malignant salivary gland tumors, i.e. adenoid cystic carcinomas and mucoepidermoid carcinomas, deletions or rare translocations involving the terminal region of the long arm of chromosome 6 , were found to be the most consistent alterations (25-28). In addition, certain types of solid tumors, and several types of leukemias and lymphomas are characterized by various deletions of 6q (29).

As novel findings, the present study detected frequent alterations on $8 \mathrm{p}(30 \%)$ and $9 \mathrm{p}(23 \%)$ in this tumor entity. Alterations on $8 \mathrm{p}$ may indicate genes involved in DNA damage response and tumorigenesis such as tumor-suppressor genes MCPH1, ANGPT2 and PINX1 at 8p23.1pter. CDKN2A and $C D K N 2 B$, located at $9 \mathrm{p} 21$, are also important candidate genes known to be involved in cell cycle regulation (Fig. 2). As these observations were not detected in previous conventional karyotyping analyses $(6,8,10)$ or comparative genomic hybridization analysis (17), they warrant particular interest in further studies.

In addition to the deletions on 22q12, gains of chromosome 22 were also a frequent event in our WT cohort. The potential candidate tumor-suppressor genes on 22q12 CHEK2 and TIMP3 were previously shown to be associated with increased risk of prostate cancer (30) and pancreatic endocrine tumors (31). Moreover, the growth factor PDGFB was found to play an essential role in the regulation of cell proliferation, cell migration and survival (32). Due to the identification of specific gains at 22q12.3qter, further analysis of PDGFB in WTs is warranted.

Furthermore, conventional karyotyping of WTs revealed a translocation $\mathrm{t}(11 ; 19)(\mathrm{q} 21 ; \mathrm{p} 13.1)(5,8,9,11)$. This translocation results in the fusion gene MAML2/CRTC1, which is common in most cases of mucoepidermoid carcinoma (MEC) and possibly indicates the derivation of certain MECs from WTs $(11,15)$. Since balanced translocations are not detectable with $\mathrm{CGH}$, no conclusions are possible concerning presentation of the $t(11 ; 19)$ translocation in our cohort.

Notably, a study analyzing a cohort of 15 primary MECs by CGH analysis revealed losses on 15q in 4 of their tumors, partly together with deletions on 8p and 22 (33). Furthermore, a microarray analysis of a salivary duct carcinoma arising in WT also revealed losses of 8,15 and 22 in addition to other alterations (34). We also observed this pattern of alterations in our WTs, particularly in those with a high number of chromosomal alterations possibly indicating chromosomal instability. Notably, in a variety of other tumor entities such as MEC, head and neck squamous cell carcinoma and prostate cancer, defined copy number alterations, e.g. loss of $8 p$, as well as the total number of imbalances are of general importance in the progression and also the metastatic potential of these tumors $(28,35)$. Collectively, all these findings support a potential role of this pattern of alterations for a more pronounced tumor type for WT. As none of the patients in this series presented with a tumor recurrence to date, we cannot address this issue in the present study. Nevertheless, our findings need to be interpreted with caution reflecting on the morphological heterogeneity in WTs. In the selected study design, it was not considered to which extent lymphoid or epithelial tumor components were analyzed. Therefore, the identification of different chromosomal aberrations may reflect the different tumor components. However, in defining significant candidate genes based on the CGH findings, one should be aware that chromosomal alterations can point to important genes in tumorigenesis, but may also be the result of chromosomal instability.

To the best of our knowledge, the present study presents the largest cohort of $30 \mathrm{WTs}$ analyzed by CGH to date. Our molecular cytogenetic analysis confirmed the findings of previous cytogenetic studies and identified new recurrent alterations as well as different patterns of chromosomal aberrations with the potential for a diagnostic impact. The presented data identified significant consensus regions that may harbor candidate genes of importance in the tumor biology of WTs. These warrant further study to assess their possible involvement in WT tumorigenesis.

\section{References}

1. Ellis GL and Auclair PL: Tumors of the salivary glands. 3rd edition. Armed Forces Institute of Pathology, Washington, 1996.

2. Teymoortash A: Head and neck: Salivary gland: Warthin's Tumors. Atlas Genet Cytogenet Oncol Haematol, April, 2008. http://AtlasGeneticsOncology.org.

3. Thangarajah T, Reddy VM, Castellanos-Arango $\mathrm{F}$ and Panarese A: Current controversies in the management of Warthin tumour. Postgrad Med J 85: 3-8, 2009.

4. Yu GY, Liu XB, Li ZL and Peng X: Smoking and the development of Warthin's tumour of the parotid gland. Br J Oral Maxillofac Surg 36: 183-185, 1998. 
5. Mark J, Dahlenfors T, Stenman G and Nordquist A: A human adenolymphoma showing the chromosomal aberrations del(7) (p12;p14-15) and $\mathrm{t}(11 ; 19)(\mathrm{q} 21 ; \mathrm{p} 12-13)$. Anticancer Res 9: $1565-1566,1989$.

6. Mark J,Dahlenfors R,Stenman G and Nordquist A: Chromosomal patterns in Warthin's tumor. A second type of human benign salivary gland neoplasm. Cancer Genet Cytogenet 46: 35-39, 1990.

7. Mark HF, Hanna I and Gnepp DR: Cytogenetic analysis of salivary gland type tumors. Oral Surg Oral Med Oral Pathol Oral Radiol Endod 82: 187-192, 1996.

8. Martins C, Fonseca I, Roque L and Soares J: Cytogenetic characterisation of Warthin's tumour. Oral Oncol 33: 344-347, 1997.

9. Bullerdiek J, Haubrich J, Meyer K and Bartnitzke S: Translocation $\mathrm{t}(11 ; 19)(\mathrm{q} 21 ; \mathrm{p} 13.1)$ as the sole chromosome abnormality in a cystadenolymphoma (Warthin's tumor) of the parotid gland. Cancer Genet Cytogenet 35: 129-132, 1988.

10. Nordkvist A, Mark J, Dahlenfors R, Bende M and Stenman G: Cytogenetic observations in 13 cystadenolymphomas (Warthin's tumours). Cancer Genet Cytogenet 76: 129-135, 1994.

11. Enlund F, Behboudi A, Andrén Y, Oberg C, Lendahl U, Mark J and Stenman G: Altered Notch signaling resulting from expression of a WAMTP1-MAML2 gene fusion in mucoepidermoid carcinomas and benign Warthin's tumors. Exp Cell Res 292: 21-28, 2004

12. Tirado Y, Williams MD, Hanna EY, Kaye FJ, Batsakis JG and El-Naggar AK: CRTC1/MAML2 fusion transcript in high grade mucoepidermoid carcinomas of salivary and thyroid glands and Warthin's tumors: implications for histogenesis and biologic behavior. Genes Chromosomes Cancer 46: 708-715, 2007.

13. Fehr A, Roser K, Belge G, Loening T and Bullerdiek J: A closer look at Warthin tumors with respect to the $\mathrm{t}(11 ; 19)$. Cancer Genet Cytogenet 180: 135-139, 2008.

14. Tonon G, Modi S, Wu L, Kubo A, Coxon AB, Komiya T, O'Neil K, Stover K, El-Naggar A, Griffin JD, Kirsch IR and Kaye FJ: t(11;19)(q21;p13) translocation in mucoepidermoid carcinoma creates a novel fusion product that disrupts a Notch signaling pathway. Nat Genet 33: 208-213, 2003.

15. Bell D, Luna MA, Weber RS, Kaye FJ and El-Naggar AK: CRTC1/MAML2 fusion transcript in Warthin's tumor and mucoepidermoid carcinoma: evidence for a common genetic association. Genes Chromosomes Cancer 47: 309-314, 2008.

16. Ogawa $\mathrm{Y}$, Hong $\mathrm{S}$, Toyosawa $\mathrm{S}$, Chang $\mathrm{CK}$ and Yagi $\mathrm{T}$ : Expression of major histocompatibility complex class II antigens and interleukin-I by epithelial cells of Warthin's tumor. Cancer 66: 2111-2117, 1990

17. Giefing M, Wierzbicka M, Rydzanicz M, Cegla R, Kujawski M and Szyfter K: Chromosomal gains and losses indicate oncogene and tumor suppressor gene candidates in salivary gland tumors. Neoplasma 55: 55-60, 2008.

18. Karhu R, Kähkönen M, Kuukasjärvi T, Pennanen S, Tirkkonen M and Kallioniemi O: Quality control of CGH: impact of metaphase chromosomes and the dynamic range of hybridization. Cytometry 28: 198-205, 1997.

19. Evdokiou A, Webb GC, Peters GB, Dobrovic A, O'Keefe DS, Forbes IJ and Cowled PA: Localization of the human growth arrest-specific gene (GAS1) to chromosome bands 9q21.3-q22, a region frequently deleted in myeloid malignancies. Genomics 18 731-733, 1993 .

20. Orlova KA and Crino PB: The tuberous sclerosis complex. Ann NY Acad Sci 1184: 87-105, 2010.

21. Lininger RA, Park WS, Man YG, Pham T, MacGrogan G, Zhuang $\mathrm{Z}$ and Tavassoli FA: $\mathrm{LOH}$ at $16 \mathrm{p} 13$ is a novel chromosomal alteration detected in benign and malignant microdissected papillary neoplasms of the breast. Hum Pathol 29: 1113-1118, 1998.
22. Kadota M, Tamaki Y, Sakita I, Komoike Y, Miyazaki M, Ooka M, Masuda N, Fujiwara Y, Ohnishi T, Tomita N, Sekimoto M, Ohue M, Ikeda T, Kobayashi T, Horii A and Monden M: Identification of a 7-cM region of frequent allelic loss on chromosome band $16 \mathrm{p} 13.3$ that is specifically associated with anaplastic thyroid carcinoma. Oncol Rep 7: 529-533, 2000.

23. Alcock HE, Stephenson TJ, Royds JA and Hammond DW: Analysis of colorectal tumor progression by microdissection and comparative genomic hybridization. Genes Chromosomes Cancer 37: 369-380, 2003.

24. Summy JM and Gallick GE: Src family kinases in tumor progression and metastasis. Cancer Metastasis Rev 22: 337-358, 2003.

25. Sandros J, Stenman G and Mark J: Cytogenetic and molecular observations in human and experimental salivary gland tumors. Cancer Genet Cytogenet 44: 153-167, 1990.

26. Jin Y, Mertens F, Limon J, Mandahl N, Wennerberg J, Dictor M, Heim S and Mitelman F: Characteristic karyotypic features in lacrimal and salivary gland carcinomas. Br J Cancer 7: 42-47, 1994.

27. Persson M, Andrén Y, Moskaluk CA, Frierson HF Jr, Cooke SL, Futreal PA, Kling T, Nelander S, Nordkvist A, Persson F and Stenman G: Clinically significant copy number alterations and complex rearrangements of MYB and NFIB in head and neck adenoid cystic carcinoma. Genes Chromosomes Cancer 51: 805-817, 2012.

28. Jee KJ, Persson M, Heikinheimo K, Passador-Santos F, Aro K, Knuutila S, Odell EW, Mäkitie A, Sundelin K, Stenman G and Leivo I: Genomic profiles and CRTC1-MAML2 fusion distinguish different subtypes of mucoepidermoid carcinoma. Mod Pathol 26: 213-222, 2013.

29. Mitelman F, Johansson B and Mertens F (eds.): Mitelman Database of Chromosome Aberrations and Gene Fusions in Cancer. http://cgap.nci.nih.gov/Chromosomes/Mitelman, 2012.

30. Cybulski C, Wokołorczyk D, Huzarski T, Byrski T, Gronwald J, Górski B, Debniak T, Masojć B, Jakubowska A, Gliniewicz B, Sikorski A, Stawicka M, Godlewski D, Kwias Z, Antczak A, Krajka K, Lauer W, Sosnowski M, Sikorska-Radek P, Bar K, Klijer R, Zdrojowy R, Małkiewicz B, Borkowski A, Borkowski T, Szwiec M, Narod SA and Lubiński J: A large germline deletion in the Chek2 kinase gene is associated with an increased risk of prostate cancer. J Med Genet 43: 863-866, 2006

31. Wild A, Ramaswamy A, Langer P, Celik I, Fendrich V, Chaloupka B, Simon B and Bartsch DK: Frequent methylationassociated silencing of the tissue inhibitor of metalloproteinase-3 gene in pancreatic endocrine tumors. J Clin Endocrinol Metab 88: 1367-1373, 2003.

32. Romashkova JA and Makarov SS: NF- $\mathrm{BB}$ is a target of AKT in anti-apoptotic PDGF signalling. Nature 401: 86-90, 1999.

33. Verdorfer I, Fehr A, Bullerdiek J, Scholz N, Brunner A, Krugmann J, Hager M, Haufe H, Mikuz G and Scholtz A: Chromosomal imbalances, 11q21 rearrangement and MECT1MAML2 fusion transcript in mucoepidermoid carcinomas of the salivary gland. Oncol Rep 22: 305-311, 2009.

34. Kim HJ, Yoo YS, Park K, Kwon JE, Kim JY and Monzon FA: Genomic aberrations in salivary duct carcinoma arising in Warthin tumor of parotid gland: DNA microarray and HER2 fluorescence in situ hybridization. Arch Pathol Lab Med 135: 1088-1091, 2011.

35. Gebhart E: Comparative genomic hybridization (CGH): ten years of substantial progress in human solid tumor molecular cytogenetics. Cytogenet Genome Res 104: 352-358, 2004. 